\title{
Jens Dexheimer ab 2015 an der Spitze von Straumann Deutschland
}

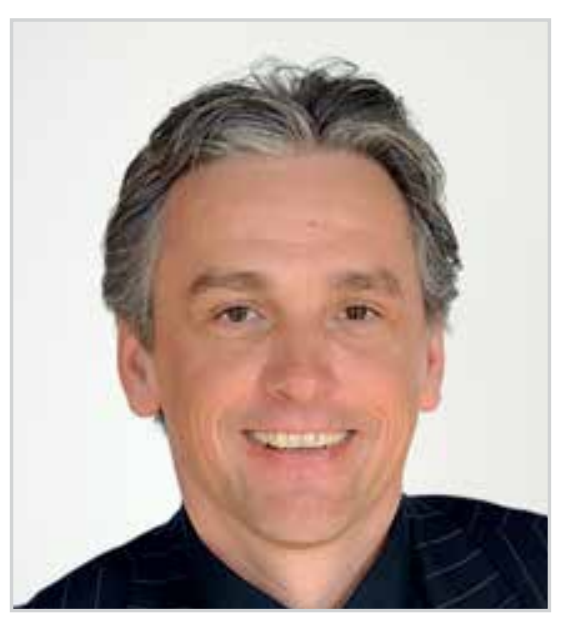

Jens Dexheimer
Jens Dexheimer übernimmt ab Januar 2015 die Leitung von Straumann Deutschland, der größten Tochtergesellschaft in Europa. Er tritt damit die Nachfolge von Wolfgang Becker an, der die Niederlassung seit 2001 führte und zur Marktführerschaft in einem der wichtigsten Märkte brachte. Damit einher geht eine erweiterte strategische Ausrichtung, die die Kunden und die Kernkompetenzen des Unternehmens noch stärker in den Mittelpunkt rückt.

Neben der Rolle des Geschäftsführers übernimmt Dexheimer auch die Vertriebsleitung für die Tochtergesellschaft in Deutschland. Somit hält er alle organisatorischen Zügel für die Umsetzung der künftigen strategischen Ausrichtung des Unternehmens und der Festigung der Marktführerschaft in der Hand.
Dexheimer war bisher Chef von Straumann Iberia und konnte in einer rezessiven Marktphase mit seinem Team die Marktführerschaft in Spanien erobern. Den Großteil der ersten Monate in seiner neuen Funktion will er nun nutzen, um Kunden der Straumann GmbH zu besuchen und sich ein Bild von ihren Bedürfnissen zu verschaffen. „Die Präsenz des Managements bei den Kunden vor Ort ist eine Grundlage für den Markterfolg“, erklärt Dexheimer. Wolfgang Becker, von dem Dexheimer den Staffelstab übernimmt, wird sich nun seiner Funktion als Vorstandsmitglied vollends widmen.

Nach einer Pressemitteilung der Straumann GmbH, Freiburg Internet: www.straumann.de 